\title{
FORMAÇÃO DOCENTE E LEGISLAÇÃO EDUCACIONAL: ENCONTROS E DESENCONTROS DA PROPOSTA DE FORMAÇÃO EM SERVIÇO DO PROJETO INSTITUCIONAL PEDAGOGIA CIDADA
}

Gilza Maria Zauhy ${ }^{1}$

Silvia Adriana Rodrigues ${ }^{2}$

\begin{abstract}
Resumo: O presente texto constitui-se em substrato de uma pesquisa desenvolvida nos anos de 2004 e 2005 junto ao Projeto Institucional Pedagogia Cidadã, cujo escopo foi o de verificar a qualidade da formação em serviço do profissional de educação infantil oferecida pelo Projeto Institucional "Pedagogia Cidadã". Além de verificar a influência do projeto em questão na formação dos profissionais da educação infantil, buscamos também examinar a qualidade do material didático do projeto, que se concretizou em Cadernos de Formação, organizados por tema ou eixos de formação e que configura o foco do trabalho ora apresentado. Desta forma, os dados aqui analisados dizem respeito apenas a um dos itens examinados, ou seja, o conteúdo do material didático utilizado no que diz respeito as normatizacões legais referentes à Educação Infantil.
\end{abstract}

\section{Introdução}

A história de atendimento à infância no Brasil remonta mais de cem anos, contudo, a inclusão das instituições de atendimento às crianças de zero a seis anos no sistema educacional regular é fato recente. Somente na década de 80 do século XX é que o atendimento em creches e pré-escolas aparece na Constituição Federal de 1988, no Capítulo da Educação, como direito da criança e dever do Estado (Artigo 208, Inciso IV). Incorporando essas premissas constitucionais, o Ministério da Educação e do Desporto elaborou uma proposta de Política de Educação Infantil, coordenada pela Secretaria de Educação Fundamental, que foi aprovada, em 1994 como a Política Nacional de Educação Infantil (Brasil, 1994). Implementá-la, entretanto, impôs vários desafios.

Barreto (1995), ao apresentar os obstáculos encontrados ressalta que, embora os avanços alcançados na área da educação infantil nas últimas décadas tenham sido significativos, um atendimento caracterizado por padrões de qualidade e de possibilidade de acesso ainda não se revela satisfatório. Com relação ao segmento específico da creche, a qualidade mostra-se ainda mais comprometida, uma vez que se desenvolveu historicamente, atendendo crianças mais pobres num modelo assistencialista.

Segundo Souza (1988, p. 13):

O contexto histórico desse atendimento tem revelado, ao longo do tempo, uma divergência de ênfase no que se refere às funções da pré-escola. Inicialmente, o atendimento proposta às classes populares foi médico e

\footnotetext{
${ }^{1}$ Professora Doutora do Departamento de Educação e da Pós Graduação em Educação da FCT/UNESP de Presidente Prudente gmzauhy@ hotmail.com

${ }^{2}$ Mestranda em Educação da FCT/UNESP de Presidente Prudente; Professora Substituta do Departamento de Educação da UFMS - Campus de Três Lagoas onlysil@uol.com.br
} 
sanitário; em seguida, passou a incorporar o aspecto nutricional e social, e só mais recentemente inclui uma preocupação educacional.

Adentramos o século XXI ecoando discursos de que a criança pequena é um sujeito de direitos, que é uma cidadã, que deve ter sua autonomia promovida e respeitada, mas na prática, percebemos que não avançamos muito no sentido de sobrepujar as desigualdades e muitas vezes o descaso para com este segmento, principalmente, no que diz respeito crianças das camadas populares.

Dentre outros, um dos mais graves problemas desta modalidade de ensino é a formação específica e adequada dos profissionais que nela atuam. Apesar dos esforços para garantir uma mínima formação específica, garantida pela LDBEN - Lei de Diretrizes e Bases da Educação Nacional (Lei 9.394/96) que estabelece como preceito ao menos a formação na modalidade normal em nível médio para os profissionais da educação infantil, o cenário apresentado não é dos mais animadores. Estudos como os de Barreto (1998) demonstram que o nível de formação dos profissionais de educação infantil e bastante baixo e precário para um atendimento pedagógico de qualidade das crianças. Desta forma, reverter este quadro problemático, significa efetivamente pensar a qualidade da formação do professor, por se constituir este como um dos fatores que coopera significativamente para a construção de uma escola de qualidade.

Dentro deste contexto, o Projeto Pedagogia Cidadã nasceu dos esforços da Universidade Estadual Paulista "Julio de Mesquita Filho" (UNESP) em levar a toda sociedade uma formação universitária de reconhecida qualidade. Para tanto, constitui-se um Grupo de Trabalho com a incumbência de elaborar a proposta pedagógica que serviu de suporte à organização do Curso de Licenciatura em Pedagogia para professores e profissionais que atuam na Educação Infantil e nas séries iniciais do Ensino Fundamental.

$\mathrm{O}$ aumento do quantitativo de crianças atendidas em creches e pré-escolas exigiu que a se comprometesse com a formação de professores para a educação infantil (0 a 6 anos). Essa exigência é grande uma vez que o atendimento desta modalidade de ensino é efetuado no âmbito municipal, que muitas vezes não dispõe de profissionais habilitados para cuidar e educar suas crianças. Com esse pressuposto estabeleceram-se parcerias com 44 Prefeituras Municipais do Estado de São Paulo, valendo-se das disposições da LDBEN.

A formação de professores em nível superior, principal razão da existência do Programa Institucional Pedagogia Cidadã, constituiu-se certamente levando em consideração o estabelecido no Artigo 62 da LDBEN:

A formação de docentes para atuar na educação básica far-se-á em nível superior, em curso de licenciatura, de graduação plena, em universidades e institutos superiores de educação, admitida, como formação mínima para o exercício do magistério na educação infantil e nas quatro primeiras séries do ensino fundamental, a oferecida em nível médio, na modalidade normal.

Por sua vez, a preocupação legal em relação a certos princípios básicos para esta formação assim se expressa na LDBEN: 


\begin{abstract}
A formação de profissionais da educação, de modo a atender aos objetivos dos diferentes níveis e modalidades de ensino e às características da cada fase do desenvolvimento do educando, terá como fundamentos:

I - a associação entre teorias e práticas, inclusive mediante a capacitação em serviço;

II - aproveitamento da formação e experiências anteriores em instituições de ensino e outras atividades. (artigo 61)
\end{abstract}

Nesta conjuntura, a iniciativa de desenvolver um programa de Formação em nível superior teve como princípio atender um universo de aproximadamente, 40.000 professores em exercício na Educação Infantil e nos anos iniciais do Ensino Fundamental ligados às redes públicas de ensino municipal que não possuíam formação em nível superior.

Neste contexto, realizou-se a pesquisa intitulada: "A formação em serviço do profissional de educação infantil no Projeto Institucional 'Pedagogia Cidadã'”, que teve como objetivo principal verificar a influência do projeto em questão na formação em serviço dos profissionais da educação infantil sob responsabilidade da coordenação de Presidente Prudente. Desta forma, os dados apresentados neste texto dizem respeito à apenas uma das categorias de análise trabalhadas, sendo ela, a qualidade do material didático utilizado no projeto, especificamente no que diz respeito as normatizacões legais referentes à Educação Infantil.

\title{
Caracterizando o objeto de investigação: o Projeto Institucional Pedagogia Cidadã
}

A formação de professores é um dos temas mais polêmicos e mais presente nas reformas educacionais brasileiras dos últimos anos, sendo que as novas exigências legais quanto à formação mínima dos profissionais docentes provocou o surgimento de inúmeras e diferentes iniciativas de formação continuada e em serviço.

Dentro destas circunstancias o Projeto Institucional Pedagogia Cidadã nasce a partir de diferentes perspectivas, que traduzem o compromisso de uma formação baseada na reflexão permanente e conhecimento construído, também, a partir da prática, que norteiam esse programa e podem ser sumariadas segundo seus mentores em três idéias mestras: formação de um professor reflexivo; desenvolvimento de saberes relacionados à ação docente; e articulação entre formação inicial e continuada. (Pedagogia Cidadã, 2003).

O curso foi organizado em 2 grandes eixos: formação de professores para a Educação Infantil e séries iniciais do Ensino Fundamental, e; formação de gestores para a unidade escolar. Neste sentido, o curso tem uma carga horária total de 3.390 horas, distribuídas em 3 anos de duração. Desenvolve-se nos ambientes de aprendizagem das prefeituras municipais participantes, coordenadas academicamente por unidades da UNESP. No plano presencial, são ministradas 24 horas/aula semanais, baseadas em textos reunidos em Cadernos de Formação, organizados por tema, disciplinas, eixos de formação ou ainda por área de conhecimento.

Ainda prevê a realização de atividades à distância, tratando-se assim de um curso presencial que utiliza recursos tecnológicos de informação e comunicação (TIC), a saber: 
- Teleconferências: geradas para todos os pólos receptores sob a responsabilidade de professores universitários da própria UNESP ou por ela convidados;

- Videoconferências: geradas nos estúdios localizados nos diversos Pólos da UNESP, proferidas por docentes-pesquisadores desta Universidade ou por educadores de reconhecida competência sobre o tema a ser trabalhado;

Para o desenvolvimento destas atividades há estúdios geradores de videoconferências, sediados nos campi da UNESP, e nas salas de aula, equipamento de recepção, cuja instalação fica sob responsabilidade financeira e técnica das prefeituras, bem como de laboratórios de informática para utilização da ferramenta de aprendizagem e biblioteca especializada.

Dentre os 3.912 alunos matriculados na primeira turma do projeto Pedagogia Cidadã, 486 deles ficaram sob responsabilidade do Pólo de Presidente Prudente, distribuídas em 09 salas de aula, localizadas em 4 municípios, e organizadas da seguinte forma: Martinópolis - 3 salas; Paraguaçu Paulista - 2 salas; Regente Feijó - 2 salas; e Rosana - 2 salas. Cada uma das salas de aula ficou sob a responsabilidade de um professor, que por sua vez encontrava-se sob a orientação de um docente da UNESP, que desenvolveu trabalho de orientação presencial nas salas de aula com frequiência semanal.

\section{Métodos e resultados}

O estudo desenvolvido enquadrou-se no campo qualitativo da pesquisa, de caráter exploratório, cuja coleta de dados deu-se a partir de análise documental realizada através de repertório direto e indireto: na aplicação de questionários com perguntas abertas e na análise do material didático utilizado no projeto em questão.

Tendo em vista o propósito principal do trabalho de investigação, quer seja, a verificação da qualidade da formação oferecida aos profissionais da educação infantil, especificamente no que diz respeito à legislação educacional, o confronto dos dados obtidos com os textos contidos nos Caderno de Formação de Educação Infantil e Legislação Educacional tornou possível tecer algumas considerações sobre a possibilidade de mudança na qualidade da educação infantil oferecida pelos profissionais matriculados no curso.

O Caderno de Formação em "Legislação Educacional" traz como objetivo tratar das principais mudanças na educação brasileira a partir do novo marco constitucional, estabelecido pela Constituição Federal de 1988 e pelas leis que sucederam o texto constitucional: LDBEN 9.394/96, Lei de criação do FUNDEF - Lei Federal n. ${ }^{\circ}$ 9.424; Resoluções e Pareceres do Conselho Nacional de Educação, bem como decretos federais que introduziram alteração da Lei Federal n. ${ }^{\circ}$ 9.394/96.

Os Cadernos propõem-se ainda, abordar as principais questões relacionadas com a Educação Básica (Educação Infantil, Ensino Fundamental e Ensino Médio) com o intuito de possibilitar aos estudantes uma melhor compreensão das políticas presentes no cenário educacional brasileiro.

A rigor, as discussões que se seguem não se encontram contidas nos Cadernos de Formação em Legislação Educacional que de maneira incontestável deveriam 
fazer parte do curso que se propôs a formar e habilitar profissionais para atuarem na educação infantil.

Desta forma, fazemos um recorte para nos determos nas questões e desafios pertinentes à educação infantil e as novas definições da legislação que deveriam ser contempladas no projeto em questão. Cabe salientar que estas questões e desafios têm efeito direto nas políticas de educação infantil, sendo este o pano de fundo que tem provocado interrogações e mesmo temores quanto ao destino da educação da criança de 0 a 6 anos.

\section{Normatizações legais da educação infantil: do embate ao debate}

A LDBEN, assim como as demais leis recentes a respeito da infância são conseqüência da Constituição Federal de 1998 que definiu uma nova doutrina em relação à criança, que é a da criança como sujeito de direitos. Desde a Constituição de 1988 ficou legalmente definida que os pais, a sociedade e o poder público têm que respeitar e garantir os direitos das crianças, definidos em seu Artigo 227 da seguinte forma:

\footnotetext{
É dever da família, da sociedade e do Estado assegurar à criança e ao adolescente, com absoluta prioridade, o direito à vida, à saúde, à alimentação, à educação, ao lazer, à profissionalização, à cultura, à dignidade, ao respeito, à liberdade e à convivência familiar e comunitária, além de colocá-los a salvo de toda forma de negligência, discriminação, exploração, violência e opressão.
}

Como afirma Craidy (2001), nem as instituições infantis, nem os pais, nem qualquer outro setor da sociedade civil ou governamental poderão dispor das crianças da maneira como bem entenderem. A rigor, todos são obrigados a respeitarem os direitos da criança e do adolescente consagrados pela Constituição Federal, que os reconheceu como cidadãos em desenvolvimento.

Outras duas grandes conquistas resultaram das definições de que os trabalhadores (homens e mulheres) têm direito à assistência gratuita aos filhos e dependentes desde o nascimento até os seis anos de idade em creches e pré-escolas; (art. $7^{\circ} / \mathrm{XXV}$ ) e que: o dever do Estado com a educação será efetivado mediante a garantia de "atendimento em creches e pré-escolas às crianças de zero a seis anos de idade (Art.208, Inciso IV)".

Deriva-se daí então, o direito das crianças e de seus pais, ou responsáveis, às creches e pré-escolas, instituições estas que passam a assumir além do caráter "cuidar" também o "educar".

A LDBEN, ao regulamentar a educação infantil, define-a como primeira etapa da educação básica (Art.21/I) que tem, por finalidade o desenvolvimento integral da criança até seis anos de idade, em seus aspectos físico, psicológico, intelectual e social, complementando a ação da família e da comunidade (Art.29). Ao definir tais finalidades, assume a creche e pré-escola, uma função de complementação e não como entendida por muitos como de substituição à ação familiar. Isso evidencia a necessidade de parceria entre as instituições, a família e a comunidade para que juntas possam oferecer a criança o que ela precisa para crescer, aprender e se desenvolver.

Prescreve ainda que cada instituição do sistema escolar, portanto incluídas as instituições de educação infantil, deverá ter sua proposta pedagógica centrada em sua clientela e contexto, adequada à sua comunidade e seus profissionais a formação mínima do 
curso normal com especialização em educação infantil, e sempre que possível o curso superior.

Para os que já trabalham em creches e pré-escolas e não têm a formação exigida deverá ser oferecida a formação em serviço. Insere-se neste contexto a proposta do projeto institucional "Pedagogia Cidadã".

É em decorrência da valorização da criança e da inserção da educação infantil na educação básica que se estabelece na LDBEN uma nova exigência de formação para os educadores, levando, principalmente, no caso das creches, a não limitar sua experiência apenas com a guarda e o cuidado de crianças, como historicamente foi tratada a formação dos profissionais de educação infantil.

Sem dúvida, representa um avanço o novo patamar de habilitação dos educadores se analisado a partir das responsabilidades contidas na LDBEN a todos os profissionais, inclusive os da educação infantil, qual seja: participar da elaboração do projeto político-pedagógico da escola/instituição infantil, contextualizando-o na realidade sociocultural da comunidade, e estimulando os pais a participarem da sua discussão, por meio da presença nas instâncias de gestão que devem existir em todas as instituições educacionais.

A participação direta do professor na elaboração do projeto é condição indispensável para que este se efetive na medida em que, nesse processo participativo, ele reconstrói e interioriza valores e concepções possibilitando o desenvolvimento de novas competências para exercer seu trabalho com qualidade. A novidade posta é a exigência de normatização que assegure propostas pedagógicas de qualidade para todos, pois é equivocada a afirmação corrente de que só agora as creches e pré-escolas se transformaram em instituições educativas. Essa exigência democrática, estabelecida em nome da igualdade de direitos, parece não estar sendo respeitada pelos poderes competentes.

Outra grande conquista é o Estatuto da Criança e do Adolescente - ECA, efetivado pela promulgação da Lei Federal 8.069/1990, que explicitou de maneira clara cada um dos direitos da criança e do adolescente, bem como os princípios que devem orientar as políticas de atendimento. A criança e o adolescente são considerados como prioridade nacional, reconhecendo-os como pessoas em condições peculiares de desenvolvimento, inserindo-os, portanto no mundo dos direitos e dos direitos humanos. Estabeleceu ainda o sistema de elaboração e fiscalização das políticas públicas voltadas para a infância. Neste intuito, o Estatuto determinou a criação dos Conselhos da Criança e do Adolescente para traçar as diretrizes políticas, e dos Conselhos Tutelares para administrar diligentemente pelo respeito aos direitos das crianças e dos adolescentes, dentre eles o direito à educação, que para as crianças de 0 a 6 anos compreenderá ao direito de acesso à creches e pré-escolas.

Passados 15 anos da promulgação do Estatuto, quais conquistas e quais desafios? A prática social com relação à infância continua sendo marcada por quais ações e posturas na esfera pública? O Estatuto está em risco? E, quanto aos recursos financeiros para a educação infantil, pois é possível fazer educação de qualidade sem recursos? Quem afinal é o responsável por pagar a conta? Estas são avaliações e discussões que não permearam as reflexões dos textos legais selecionados, sendo então que não há garantia de que estas questões tenham sido contempladas no processo de formação de educadores da infância oferecido pelo Projeto Pedagogia Cidadã. 
Não se sustenta mais o juízo que o senso comum, por desinformação, faz e propaga da educação infantil, atribuindo a sua responsabilidade "exclusivamente" aos municípios. O que se deve concluir, a partir de um olhar mais cuidadoso é que a oferta e a manutenção dessa modalidade de ensino comporta um regime de cooperação e colaboração entre parceiros, envolvendo o poder público municipal (como uma das suas atribuições prioritárias), o poder público estadual e o poder público federal (subsidiariamente), além da sociedade civil, nas suas variadas formas de organização.

Discutiu-se ao descrever o ordenamento legal do FUNDEF - Fundo de Manutenção de Desenvolvimento do Ensino fundamental - o impacto sucateador na educação infantil, a desaceleração que está provocando no crescimento da educação infantil e conseqüente influência na valorização deste nível de ensino e de seus profissionais? E, o FUNDEB - Fundo de Manutenção de Desenvolvimento da Educação Básica - não vai dar, como seu antecessor FUNDEF, motivo a críticas? Há algum risco de a educação infantil não ser tratada adequadamente no FUNDEB? Sim, há!

A Proposta de Emenda Constitucional (PEC) que cria o FUNDEB trata, realmente, da educação básica, explicitando as três etapas que a compõem e que serão atendidas com os recursos do novo Fundo. No entanto, a nova redação proposta para o Art. 60 $\S 3 .^{\circ}$ do Ato das Disposições Constitucionais Transitórias - ADCT, determina que a lei vai definir a distribuição proporcional dos recursos entre pré-escola, ensino fundamental e médio. Tivesse dito "educação infantill", a creche estaria certamente contemplada, no entanto ao não dizê-lo, excluiu a sub-etapa da educação básica que é a creche. O colapso das creches brasileiras anuncia-se conforme denúncia de Campos e Rosemberg (2005), ao excluir as crianças de 0 a 3 anos do financiamento para educação básica, em flagrante desrespeito à Constituição e à Lei de Diretrizes a Bases da Educação Nacional.

Diante do exposto, reafirmamos a "falta" crucial no âmbito da formação de profissionais para a educação infantil, de estudos e discussões amparadas pelas normatizações legais em confronto com a realidade diretamente vinculada ao seu campo de atuação. Esta constatação se traduz nas seguintes palavras de Filho (2005, p. 71):

Os saberes pedagógicos indispensáveis à formação dos decentes são construídos na prática, quando os conhecimentos sobre a educação ou sobre a pedagogia são reelaborados no confronto com a realidade da escola, do processo educacional.

\section{Considerações Finais}

A partir da promulgação da Constituição Federal em 1988, do Estatuto da Criança e do Adolescente em 1990, da Lei de Diretrizes e Bases da Educação Nacional em 1996, das Diretrizes Curriculares Nacionais em 1999, do Plano Nacional de Educação em 2001 e, ainda, das legislações educacionais em nível estadual e municipal, mudanças vêm sendo inseridas nos campos administrativo e pedagógico das instituições de educação infantil - creches e pré-escolas. As recentes resoluções legais dão destaque especial, dentre vários aspectos, a incorporação das instituições que atendem crianças de 0 a 6 anos aos sistemas de ensino; a implementação de projetos pedagógicos que atentem para a criança pequena na sua completitude; a articulação com as famílias e a comunidade local; a integralização 
cuidar/educar no cotidiano das instituições infantis e a formação específica dos seus profissionais.

Diante destas novas demandas propostas, o cenário nacional, tendo em vista a sujeição da letra destas leis à interpretações diversas, é palco, dentre outras consequiências, do desmoronamento de programas já sólidos, a transformação de iniciativas inovadoras em algo inexeqüível ou, ainda, a imposição do modelo escolarizante do ensino fundamental às instituições de educação infantil.

Em contrapartida, temos uma tradição cultural e política que sempre foi cunhada pela distância entre a legislação e a realidade e, até mesmo, como afirma Campos (2002, p.27): "pela oposição entre aquilo que gostamos de colocar no papel e o que de fato fazemos na realidade".

No campo das políticas direcionadas à infância temos tido historicamente avanços, retrocessos e impasses, ganhando muitas vezes no discurso, perdendo, contudo, nas ações concretas. Em relação à situação da infância e às políticas voltadas às crianças de 0 a 6 anos, no Brasil, temos ganhos reais: "atendíamos cerca de 3,51\% das 21 milhões de crianças menores de 7 anos em 1975; atendemos quase 30\% das pouco mais de 21 milhões de crianças em 2000. Ora, 30\% são muito mais que 3,5\%, mas ainda estamos muito longe de 100\%."(Kramer, 2002, p. 118).

Neste cenário de desencontros, avanços e desafios, no que se refere a legislação, as políticas nacionais de educação infantil e a realidade, insere-se a discussão sobre a formação de professores de educação infantil, propósito do Projeto Institucional "Pedagogia Cidadã".

Como enfrentar, por exemplo, a situação do grande número de professoresleigos que se encontram trabalhando em nossas instituições de educação infantil? Nas disposições transitórias da LDBEN aparece que, até o final da Década da Educação, a iniciarse um ano a partir da publicação daquela lei, "Somente serão admitidos professores habilitados em nível superior ou formados por treinamento em serviço". (Artigo 87 § 4. ${ }^{\circ}$ )

Uma leitura cuidadosa desse artigo sugere que o mesmo se refere ao ensino fundamental. Não se aplicaria, portanto, à Educação Infantil. O Conselho Nacional de Educação - CNE deverá se posicionar quanto a isto num futuro próximo mas na compreensão de vários conselheiros, na Educação Infantil continuaria a valer o dispositivo no artigo 62 da Lei 9.394/96. O requisito mínimo seria então o curso normal em nível médio. Posicionamento que ocorreu quando o Parecer sobre o assunto (CNE/CEB 03/2003) foi aprovado em 2005.

A Lei n. ${ }^{\circ}$ 9.394/96 dispõe sobre os princípios de valorização dos profissionais da educação. O requisito é ser a creche dirigida por adulto habilitado na área da educação, podendo contar com outros profissionais de outras formações para com eles definir os caminhos básicos e dividir as tarefas coletivamente pensadas. $\mathrm{O}$ trabalho junto às crianças na creche é compreendido como sendo exercido por professores, com formação mínima de curso normal em nível médio.

Para Rosemberg (2002) a inclusão da creche no sistema de ensino requer investimentos em educação permanente e nas condições de trabalho de seus educadores. Exige também repensar o modelo internalizado pelos educadores sobre o que significa uma 
instituição de educação infantil para a faixa etária de 0 a 6 anos. Para muitos, este deve tornarse próximo de um modelo de ensino fundamental (ainda não superado em muitos lugares), exigindo da criança períodos extensos de imobilidade e de atenção a um único estímulo.

O cenário exposto permite afirmar que o material didático elaborado para tratar da legislacão educacional brasileira, não apresentou aos alunos matriculados no Projeto Institucional "Pedagogia Cidadã" conteúdos, reflexões pertinentes às questões expostas no decorrer deste texto que atingem diretamente as políticas públicas voltadas para a educação infantil. Omissão que se não impediu, certamente dificultou compreender o real significado do direito da criança pequena à educação. Portanto, crenças e concepções "limitadas" sobre o que é essencial no âmbito da educação infantil podem continuar arraigadas no ideário pedagógico dos nossos profissionais da educação infantil, sendo este ideário traduzido no discurso e prática docente cotidianos.

Se constatamos "falhas" e "faltas" no processo de formação de profissionais da educação infantil referentes à legislação educacional que justifica e apóia legalmente o direito à criança à educação (dentre outros), ao oferecer caminhos para concretizar o atendimento à infância, constatamos também a mesma deficiência nos conteúdos voltados exclusivamente à esta faixa etária, ou seja no caderno de formação intitulado "Educação Infantil".

Esta é uma falta grave para um programa que se propôs a habilitar e credenciar profissionais para atuarem neste nível de ensino, pois estes fatos, indubitavelmente ocasionaram uma visão artificial sobre as formas de trabalho com as crianças de 0 a 6 anos, sedimentando uma prática já enraizada pelo "controle do tempo" e a "escolarização precoce" que desconsidera que a criança "é cidadã, com direitos sociais, dentre eles o direito a uma educação de qualidade em todos os níveis" (Kramer apud Sanches, 2003, p.34).

Portanto, é necessário registrar que o projeto deixou lagunas sérias na formação do profissional da educação infantil, a propalada busca da vinculação teoria e prática no processo ensino-aprendizagem não foi considerada. Admitimos a possibilidade de um impacto positivo do Projeto Pedagogia Cidadã na vida profissional dos professores-alunos em termos de aproveitamento de alguns conteúdos, também em termos de vivência cultural diferenciada, mas apesar de a proposta e a oportunidade de formação serem louváveis, a forma de organização, o material didático e a condução do processo de formação estão muito aquém do desejado, inferior ao que se espera de um projeto de formação e capacitação de profissionais para atuarem na educação de crianças de 0 a 6 anos. Em outros termos, o cabe dizer que o compromisso de uma formação baseada na reflexão permanente e no conhecimento construído a partir da prática contido na proposta do projeto não foi integralmente cumprido...

\section{Referências bibliográficas}

Barreto, A. M. R. F. (1998). Situação da educação infantil no Brasil. Em: Brasil, Ministério da Educação e do Desporto. Secretaria de Educação Fundamental. Subsídios para o credenciamento e funcionamento de instituições de educação infantil. Brasília: MEC/SEF. 
Campinas, n.37.

(1995). Educação Infantil no Brasil: desafios colocados. Cadernos CEDES,

Brasil. (1995). Ministério da Educação e do Desporto. Critérios para um atendimento em creches que respeite os direitos fundamentais das crianças. Brasília, MEC/SEF/DPE/Copedi. . (1994). Ministério da Educação e do Desporto. Educação Infantil no Brasil: situação atual. Brasília: MEC/SEF/DPE/Coedi.

Brasil, (1996). Lei de Diretrizes e Bases da Educação Nacional n. o 9394/96. Brasília/DF.

Bujes, M. I. E. (2001). Escola Infantil: Para que te quero? En: Craidy, M.; Kaercher, G.E. P. da S. (org.) Educação Infantil: Para que te quero? (pp 13-22). Porto Alegre: Artmed Editora.

Campos, M. M. (2002). A Legislação e as políticas nacionais de educação Infantil e a realidade: desencontros e desafios. En: Machado, M. L. de A. (org.). Encontros e desencontros em educação infantil. (pp 27-34). São Paulo: Cortez.

Craidy,C.M. (2001). A Educação Infantil e as Novas Definições da Legislação. En: Craidy.C. M e Kaercher, E.P. da S. (orgs). Educação Infantil: para que te quero? (pp 23-26). Porto Alegre: Artmed Editora.

Didonet, V. (2005) O FUNDEB e a Educação Infantil. (texto mimeo)

Filho, J. C. P. (2005). A política nacional de formação de professores. In: Cadernos de formação: Legislação Nacional. João Cardoso Palma Filho, (org.). (pp 61-76). São Paulo: UNESP. Pró-reitoria de Graduação, v. 1.

Pedagogia Cidadã: Cadernos de Formação: Legislação Nacional. (2005). João Cardoso Palma Filho (org.). São Paulo: UNESP. Pró-reitoria de Graduação, v. 1 e 2.

Pedagogia Cidadã: Cadernos de Formação: Módulo Introdutório. (2003). Wilson Galhego Garcia (coord.). São Paulo: UNESP. Pró-reitoria de Graduação.

Rosemberg, F. (2002). Do embate para o debate: o embate assistência e educação na conjuntura nacional e internacional. En: Machado, M. L. de A. (org.) Encontros e Desencontros em educação infantil. (pp 63-78). São Paulo: Cortez.

Silva, I. de O. (2001) Profissionais da educação infantil: formação e construção de identidades. São Paulo: Cortez. (Coleção Questões da Nossa Época: v. 85). 